\title{
Exploring Existence of Host-Guest Inclusion Complex of $\beta$-Cyclodextrin of a Biologically Active Compound with the Manifestation of Diverse Interactions
}

\author{
Habibur Rahaman ${ }^{\text {b }}$, Niloy Roy ${ }^{a}$, Aditi Roy ${ }^{a}$, Samapika Ray ${ }^{\text {a }}$, Mahendra Nath Roy ${ }^{\text {a* }}$ \\ ${ }^{a}$ Department of Chemistry, University of North Bengal, Darjeeling, 734013, India \\ ${ }^{b}$ Pedong Government College, Kalimpong, 734311, India
}

\begin{abstract}
The host-guest interaction of p-nitro benzaldehyde as guest $\beta$-Cyclodextrins have been investigated which have significant applications in the field of medicine such as controlled drug delivery. The $1 \mathrm{H}$ NMR study confirms the formation of inclusion complex while surface tension and conductivity studies support the formation inclusion complex with $1: 1$ stoichiometry. The stoichiometry of the inclusion complex was also supported with Job's plot method by UV-Visible spectroscopy. FT-IR spectra and SEM study also support the inclusion process. Association constants of the inclusion complexes have been calculated using the Benesi-Hildebrand method, while the thermodynamic parameters have been estimated with the help of van't Hoff equation.
\end{abstract}

\section{Keywords:}

B-Cyclodextrin (B-CD);

Para Nitro-Benzaldehyde (PNB);

Inclusion Complex (IC);

Scanning Electron Microscope (SEM).

Article History:

Received: 13 August 2018

Accepted: 18 October 2018

\section{1- Introduction}

Cyclodextrins (CD) are macro cyclic oligosaccharides composed of repeating $\alpha$-D-glucopyranose units. Three types of CDs are $\alpha, \beta$ and $\gamma$-CD with 6,7 and 8 glucopyranoside units, respectively (Figure 1) [1, 2]. The cyclic orientation of these units gives conical or truncated cone structure with a hydrophobic interior and a hydrophilic exterior. This unique structure permits CD to form host-guest inclusion complexes with different sized guest molecules [3]. The chemical stability of guest molecule can be explained on the basis of the van der Waals attraction, hydrogen bonding and hydrophobic attractions, etc. [4]. Due to its wide applicability, CDs used in different areas, such as the cosmetics, food, medicine, hygiene, nano materials and agro industries [5]. Inclusion complex of CDs have been used in aqueous solubility enhancement of poorly soluble compounds to increase their bioavailability. Among CD family, $\beta$-cyclodextrin is the most widely used one due to the low cost.

p-nitro benzaldehyde (PNB) is a very useful compound in organic synthesis. It also has applications in medicinal chemistry. (Scheme2). In this present work we attempt to ascertain the formation and nature of inclusion complex $\beta$-CD with PNB in aqueous environment by spectroscopic and physicochemical studies. Our aim is to explore the formation, carrying and controlled release of PNB by forming IC with CD without any chemical and biological modification of the guest molecule.

\section{2- Experimental Section}

\section{2-1- Source and Purity of Samples}

P-nitro benzaldehyde and $\beta$-cyclodextrin of puriss grade were bought from Sigma Aldrich, Germany and used as purchased. The mass fraction purity of PNB and $\beta$-cyclodextrin are $\geq 0.99$ and $\geq 0.98$ respectively.

\footnotetext{
* CONTACT: Mahendraroy2002@yahoo.co.in

DOI: http://dx.doi.org/10.28991/esj-2018-01149

(C) This is an open access article under the CC-BY license (https://creativecommons.org/licenses/by/4.0/).
} 

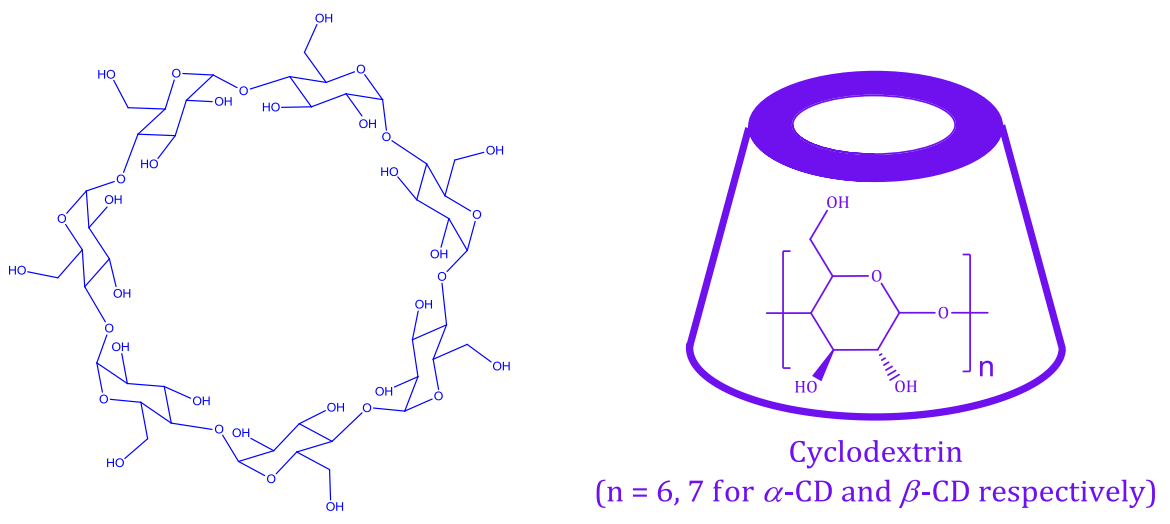

Figure 1. Structure of cyclodextrin molecules.
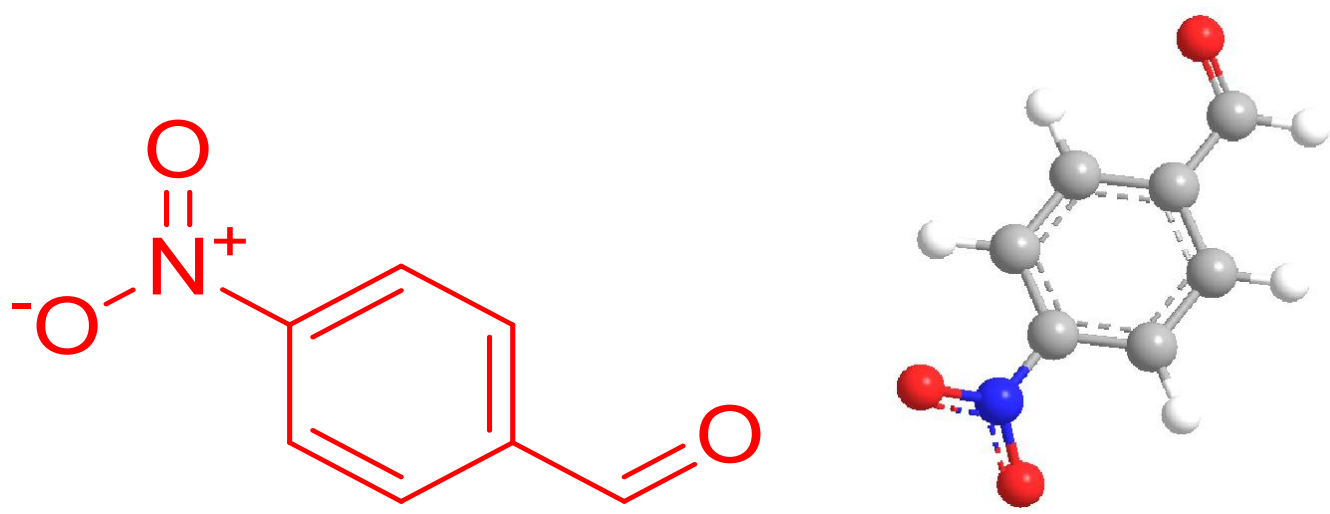

Figure 2. Two dimensional and three dimensional structure of PNB

\section{2-2- Apparatus and Procedure}

The guest molecule PNB and the $\beta$-CDs are freely soluble in triply distilled, deionized and degassed water. The stock solutions of PNB and aqueous CD were prepared by mass at 298.15 K. Mettler Toledo AG-285(uncertainty $0.0001 \mathrm{~g}$ ) was used for weighing.

UV-visible spectra were taken by JASCO V-530 UV/VIS Spectrophotometer, with an uncertainty in wavelength as $\pm 2 \mathrm{~nm}$. The temperature during experiment is kept constant using a digital thermostat.

${ }^{1} \mathrm{H}$ NMR spectra were taken in $\mathrm{D}_{2} \mathrm{O}$ at $300 \mathrm{MHz}$ with help of Bruker Advance instrument at 298.15 K. Signals are mentioned as $\delta$ values in ppm. The internal standard is $\mathrm{D}_{2} \mathrm{O}$ (protonated signal at $4.79 \mathrm{ppm}$ ). Data are cited as chemical shift.

The surface tension study was performed with platinum ring detachment technique using a Tensiometer (K9, KRSS; Germany). The temperature is maintained at $298.15 \mathrm{~K}$ by circulation of thermostated water through a double wall glass vessel containing the solution. The accuracy of the instrument is about $\pm 0.1 \mathrm{mN} \mathrm{m}^{-1}$.

Conductivities of the solutions are measured using a Mettler Toledo Seven Multi conductivity meter having uncertainty $1.0 \mu \mathrm{Sm}^{-1}$ having uncertainty $\pm 0.01 \mathrm{~K}$. Thermostated water bath kept the temperature constant at 298.15 throughout the experiment. HPLC grade water was used with specific conductance $6.01 \mathrm{Sm}^{-1}$. The conductivity cell was calibrated using $0.01 \mathrm{M}$ aqueous $\mathrm{KCl}$ solution.

Fourier transform infrared (FT-IR) spectra were recorded on a Perkin Elmer FT-IR spectrometer according to the $\mathrm{KBr}$ disk technique. Samples were prepared as $\mathrm{KBr}$ disks with $1 \mathrm{mg}$ complex and $100 \mathrm{mg} \mathrm{KBr}$. The FTIR measurements were performed in the scanning range of $4000-400 \mathrm{~cm}^{-1}$ at room temperature.

The solid inclusion complex [ $\beta-\mathrm{CD}+\mathrm{PNB}]$ has been prepared taking 1:1 molar ratio of both the PNB and CD. In this case $1.0 \mathrm{mmol} \mathrm{CD}$ was dissolved in $20 \mathrm{~mL}$ water and $1.0 \mathrm{mmol} \mathrm{PNB}$ was dissolved in $20 \mathrm{~mL}$ ethanol and stirred separately for $4 \mathrm{hrs}$. Then the ethanol solution of PNB was added drop wise to the aqueous CD solution. The mixture was then allowed to stir for $72 \mathrm{hrs}$ at $50-55^{\circ} \mathrm{C}$. It was filtered at this temperature, then cooled to $5^{\circ} \mathrm{C}$ and kept for $12 \mathrm{hrs}$. The resulting suspension was filtered and the white polycrystalline powder was found, which was washed with ethanol and dried in air. 


\section{3- Result and Discussion}

\section{3-1-Job Plot Demonstrates the Stoichiometry of the Host-Guest Inclusion Complex}

The stoichiometry of the host guest inclusion complex can be predicted with the help of Job's method of continuous variation using UV-Visible spectra [6]. The difference of absorbance of PNB in presence and absence of $\beta$-CD was calculated and designated as $\Delta \mathrm{A}$. Then a plot is constructed taking $\Delta \mathrm{A} \times \mathrm{R}$ against $\mathrm{R}$ where $\mathrm{R}=[\mathrm{PNB}] /([\mathrm{PNB}]+[\mathrm{CD}])$. (Figure 3)Job plots are constructed with variation of mole fraction of PNB in the range of 0-1[7, 8]. Absorbance values were measured at $293 \mathrm{~nm}$ at $298 \mathrm{~K}$ for a series of solutions. (Table 1) The stoichiometry of the inclusion complex can be found with the value of $\mathrm{R}$ at the point of maximum deviation. $(\mathrm{R}=0.5$ for $1: 1$ complexes; $\mathrm{R}=0.33$ for $1: 2$ complexes; $\mathrm{R}=0.66$ for $2: 1$ complexes) $[9,10]$. In this study the plot show maxima at $\mathrm{R}=0.5$ which means that the inclusion complex was formed with 1:1 molar ratio of PNB and $\beta-C D$.

Table 1. Data for the Job plot performed by UV-Vis spectroscopy for PNB- $\beta$-CD system at 298.15K ${ }^{a}$

\begin{tabular}{|c|c|c|c|c|c|c|c|}
\hline $\operatorname{PNB}(\mathbf{m L})$ & $\beta-C D(m L)$ & PNB $(\mu \mathrm{M})$ & $\beta-\mathrm{CD}(\mu \mathrm{M})$ & {$[\mathrm{PNB}] /([\mathrm{PNB}]+[\boldsymbol{\beta}-\mathrm{CD}])$} & Absorbance (A) & $\Delta \mathbf{A}$ & $\Delta \mathrm{A} \times[\mathrm{PNB}] /([\mathrm{PNB}]+[\beta-\mathrm{CD}])$ \\
\hline 0.0 & 1.0 & 0 & 100 & 0.0 & 0.0000 & 0.7420 & 0.0000 \\
\hline 0.1 & 0.9 & 10 & 90 & 0.1 & 0.0636225 & 0.6783 & 0.0678 \\
\hline 0.2 & 0.8 & 20 & 80 & 0.2 & 0.1380672 & 0.6039 & 0.1208 \\
\hline 0.3 & 0.7 & 30 & 70 & 0.3 & 0.2318311 & 0.5101 & 0.1530 \\
\hline 0.4 & 0.6 & 40 & 60 & 0.4 & 0.2906623 & 0.4513 & 0.1805 \\
\hline 0.5 & 0.5 & 50 & 50 & 0.5 & 0.3502874 & 0.3917 & 0.1958 \\
\hline 0.6 & 0.4 & 60 & 40 & 0.6 & 0.4292407 & 0.3127 & 0.1876 \\
\hline 0.7 & 0.3 & 70 & 30 & 0.7 & 0.4997888 & 0.2422 & 0.1695 \\
\hline 0.8 & 0.2 & 80 & 20 & 0.8 & 0.5812507 & 0.1607 & 0.1286 \\
\hline 1.0 & 0.0 & 100 & 0 & 1.0 & 0.7419558 & 0.0000 & 0.0000 \\
\hline
\end{tabular}

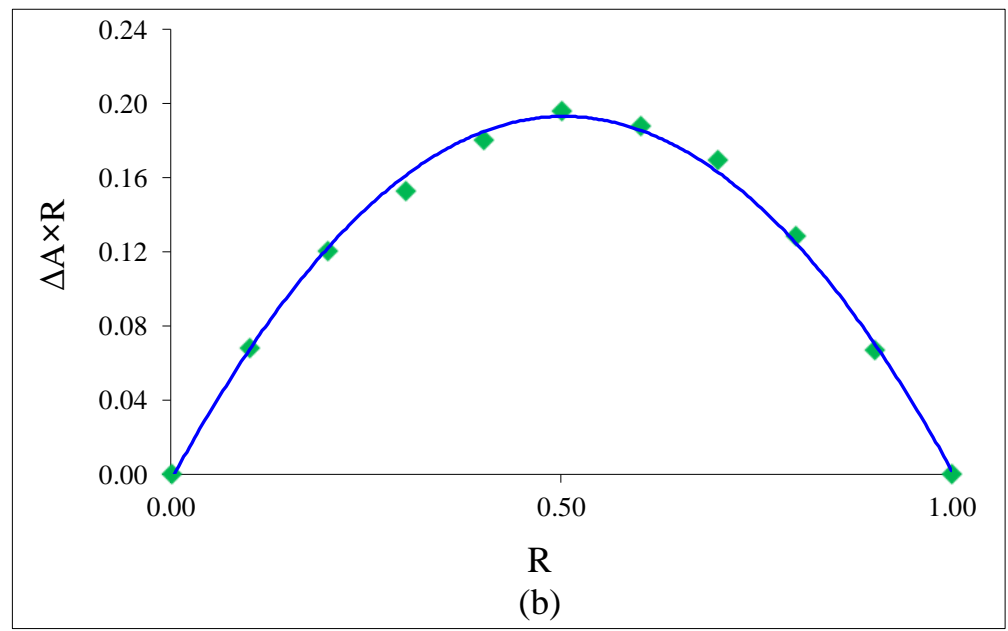

Figure 3. Job plot of (b) PB- $\beta-C D$ system at $\lambda_{\max }=243 \mathrm{~nm}$ at $298.15 \mathrm{~K} . \mathrm{R}=[\mathrm{PNB}] /([\mathrm{PnB}]+[\mathrm{CD}]), \Delta \mathrm{A}=$ absorbance difference of PNB without and with $\beta-C D$

\section{3-2- 1H-NMR Study}

1H-NMR study gives us valuable information about the formation of inclusion complex between PNB and $\beta$-CD [11]. When the guest PNB molecule inserts into the hydrophobic cavity of $\beta$-CD molecule the protons of both PNB and $\beta$-CD show considerable chemical shift. The positions of different protons in the CD molecule are shown in scheme. The H3 and H5 protons are placed in the cavity while H1, H2 and H4 are located outside the cavity. (Figure 4) H3 is situated near the wider rim and H5 is close to the narrower rim $[12,13]$. The respective $\delta$ values of PNB, $\beta$-CD and inclusion complex are mentioned in Table 2. The protons of PNB and $\beta-\mathrm{CD}$ show considerable upfield shift in the spectra of inclusion complex. (Figure 5) From NMR data it can be concluded that the aromatic protons of PNB interacts more with the $\mathrm{H} 3$ protons of $\beta-\mathrm{CD}$ in comparison to $\mathrm{H} 5$ perhaps due to the reason that the PNB molecule enters in the hydrophobic cavity from the wider rim. All the protons of both host and guest show considerable chemical shift due to 
change of environment after forming inclusion complex. The H6 proton remains unaffected suggesting PNB enters from wider end.

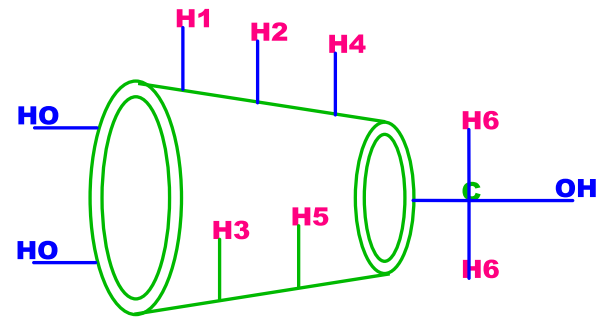

Figure 4. Truncated conical structure of $\beta$-Cyclodextrin.

Table 2. ${ }^{1} \mathrm{H}$ NMR data of PNB, $\beta$-CD and inclusion complex

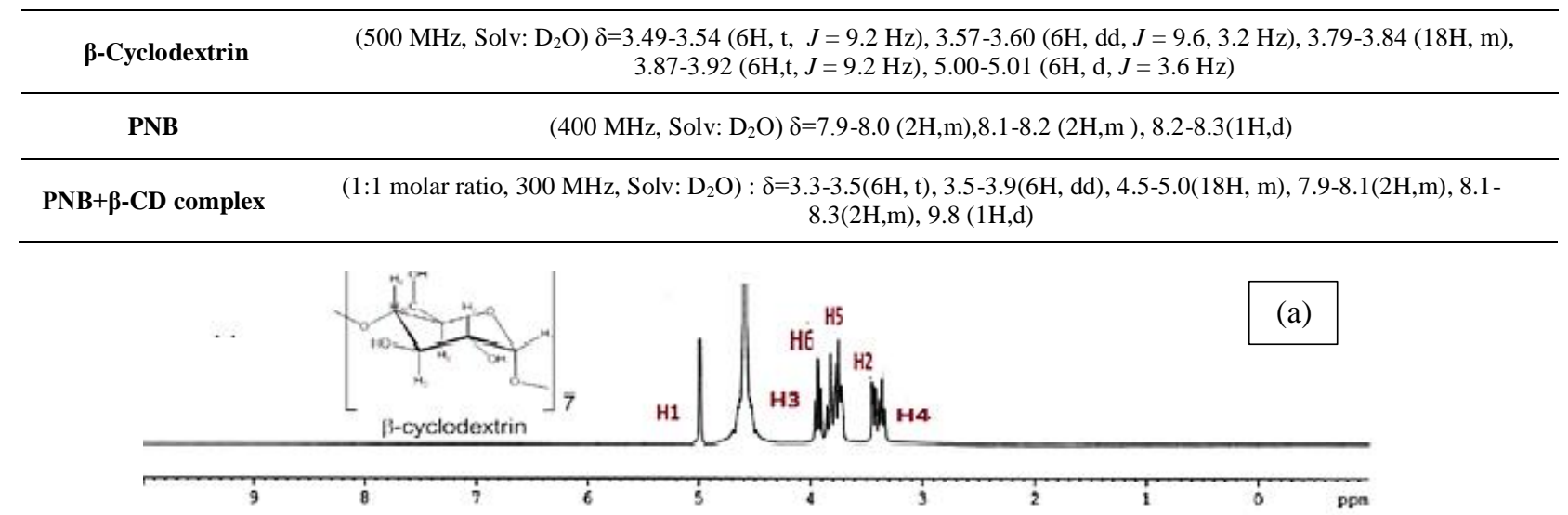

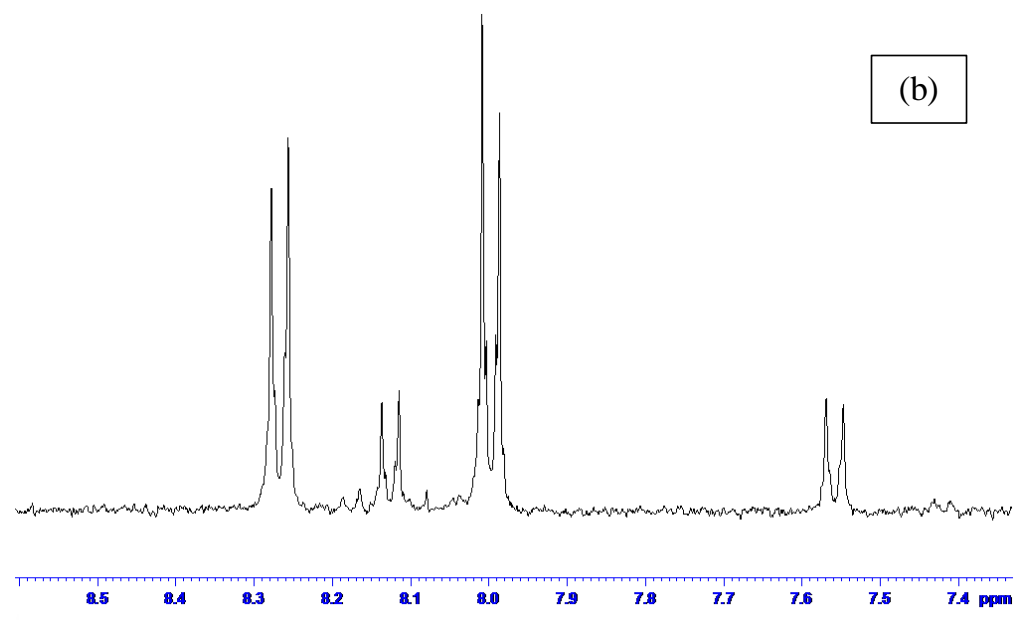

(c)

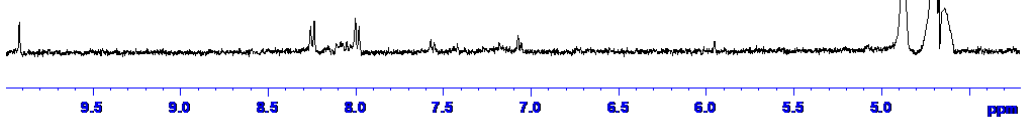

Figure 5. H NMR Spectra of (a) $\beta-C D$ (b) PNB and (c) 1:1 molar ratio of $\beta-C D+P N B$ in $\mathrm{D}_{2} \mathrm{O}$ in 298.15 K. 


\section{3-3- Surface Tension Study Confirms the Stoichiometry of the Inclusion Complex}

Cyclodextrin is freely soluble in water. The aqueous solution of $\beta$ - $\mathrm{CD}$ does not show any notable change with increasing concentration [14]. The guest molecule p-nitro benzaldehyde shows surfactant like behavior due to its structure. This means that the presence of PNB in water reduces the surface tension value $(\gamma)$ of water. In this experiment the $\gamma$ values of PNB has been measured with increasing concentration of host $\beta$-CD at 298.15 K. (Table 3) The aqueous solution of PNB shows a regular increase with increasing concentration of host $\beta$-CD. Perhaps this occurs due to the removal of surface active PNB molecules from the solution into the hydrophobic cavity of $\beta$-CD after forming the inclusion complex. The surface tension plot also contains a sharp break point which is indication of the formation of inclusion complex with 1:1 stoichiometry (Figure 6) [15, 16]. Appearance of more number of break points in the surface tension curves reveal more complex stoichiometry such as 1:2, 2:1, 2:2 etc. the value of $\gamma$ at the break point with corresponding concentration of $\beta-\mathrm{CD}$ is listed in table.

Table 3. Data for surface tension and conductivity study of aqueous PNB- $\beta$-CD system at $298.15 K^{a}$

\begin{tabular}{|c|c|c|c|c|c|}
\hline $\begin{array}{c}\text { Volm of B-CD } \\
(\mathrm{mL})\end{array}$ & $\begin{array}{c}\text { Total volm } \\
(\mathrm{mL})\end{array}$ & $\begin{array}{c}\text { Conc of } \\
\text { PNB }(\mathbf{m M})\end{array}$ & $\begin{array}{c}\text { Conc of } \beta-C D \\
(\mathbf{m M})\end{array}$ & 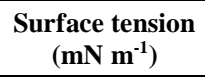 & $\begin{array}{c}\text { Conductuvity } \\
\left(\mathrm{mS} \mathrm{m}^{-1}\right)\end{array}$ \\
\hline 0 & 10 & 10.000 & 0.000 & 54.4 & 22.2 \\
\hline 1 & 11 & 9.091 & 0.909 & 56.1 & 21.2 \\
\hline 2 & 12 & 8.333 & 1.667 & 57.6 & 20.3 \\
\hline 3 & 13 & 7.692 & 2.308 & 58.8 & 19.6 \\
\hline 4 & 14 & 7.143 & 2.857 & 60.1 & 19.1 \\
\hline 5 & 15 & 6.667 & 3.333 & 61.1 & 18.5 \\
\hline 6 & 16 & 6.250 & 3.750 & 61.9 & 18 \\
\hline 7 & 17 & 5.882 & 4.118 & 62.7 & 17.6 \\
\hline 8 & 18 & 5.556 & 4.444 & 63.5 & 17.1 \\
\hline 9 & 19 & 5.263 & 4.737 & 64.2 & 16.7 \\
\hline 10 & 20 & 5.000 & 5.000 & 64.7 & 16.2 \\
\hline 11 & 21 & 4.762 & 5.238 & 64.9 & 16 \\
\hline 12 & 22 & 4.545 & 5.455 & 65.1 & 15.9 \\
\hline 13 & 23 & 4.348 & 5.652 & 65.3 & 15.8 \\
\hline 14 & 24 & 4.167 & 5.833 & 65.5 & 15.7 \\
\hline 15 & 25 & 4.000 & 6.000 & 65.7 & 15.6 \\
\hline 16 & 26 & 3.846 & 6.154 & 65.8 & 15.5 \\
\hline 17 & 27 & 3.704 & 6.296 & 65.9 & 15.4 \\
\hline 18 & 28 & 3.571 & 6.429 & 66.0 & 15.3 \\
\hline 19 & 29 & 3.448 & 6.552 & 66.1 & 15.2 \\
\hline 20 & 30 & 3.333 & 6.667 & 66.2 & 15.1 \\
\hline
\end{tabular}

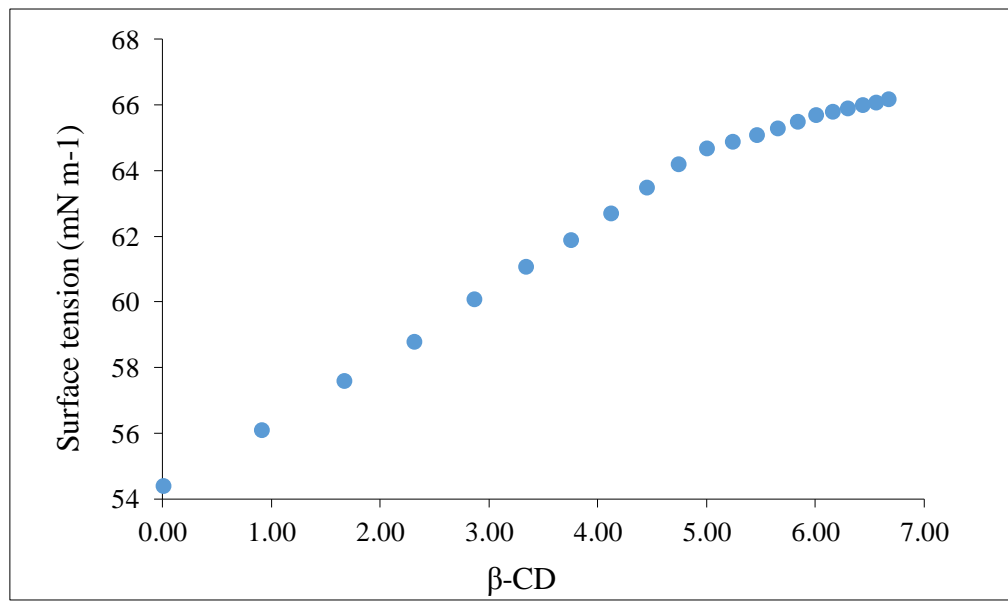

Figure 6. Variation of surface tension of aqueous PNB solution with increasing concentration of $\beta$-CD at 298.15K.

\section{3-4- Conductivity Study Again Proves the Stoichiometry of the Inclusion Complex}

The formation of inclusion complex is again confirmed with the help of conductivity study [17, 18]. The guest 
molecule PNB exists in ionic form in aqueous solution having a measureable value of $\kappa$. In this study we have added aqueous $\mathrm{CD}$ solution to the aqueous solution of PNB; it has been found that $\kappa$ value shows a regular declining trend. It is again probably due to insertion of PNB molecules from the solution to the hydrophobic cavity of CD. At certain concentration of both the host and guest molecules a single break point appeared in the conductivity plot, this confirms the formation of inclusion complex. (Figure 7) The value of $\kappa$ with corresponding concentration of $\beta$-CD is listed in Table 3 [19]. The appearance of single breakpoint again suggests the stoichiometry of the inclusion complex 1:1.

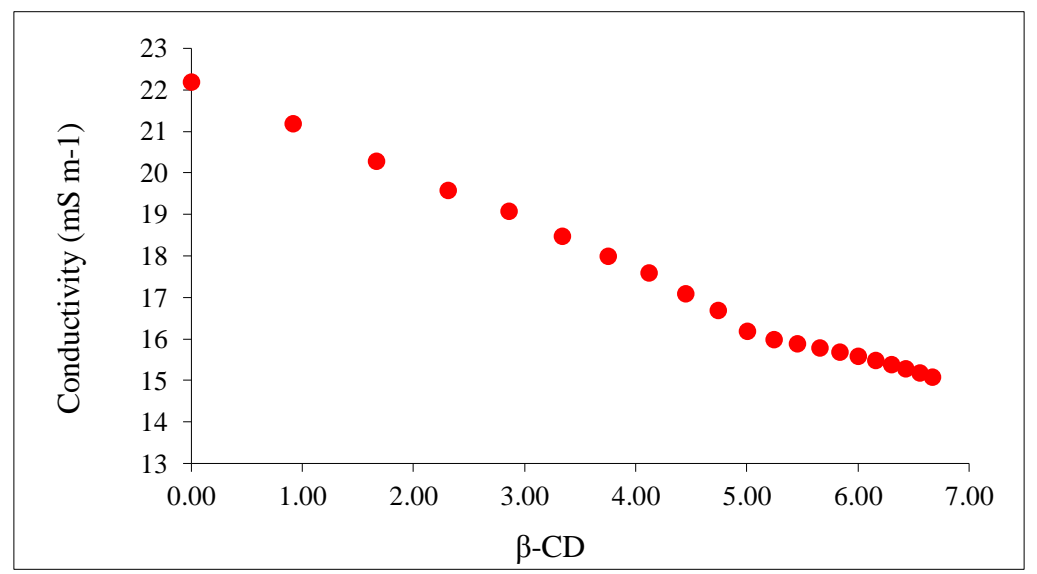

Figure 7. Variation of conductivity of aqueous PNB solution with increasing concentration $\beta-C D$ at 298.15K.

\section{3-5- Association Constants and Thermodynamic Parameters}

The association constant $\mathrm{K}_{\mathrm{a}}$ of the inclusion complex of PNB with $\beta$-CD can be calculated from UV visible spectra. When the PNB molecule enters into the cavity of $\beta$-CD the environment of the guest changes, it results in the change of molar extinction coefficient $\varepsilon$ [20]. The value of binding constant has been determined from the double reciprocal plots on the basis of Benesi-Hildebrand method which can be stated as:

$$
\frac{1}{\Delta \mathrm{A}}=\frac{1}{\Delta \varepsilon[\mathrm{PNB}] \mathrm{K}_{\mathrm{a}}} \times \frac{1}{[\mathrm{CD}]}+\frac{1}{\Delta \varepsilon[\mathrm{PNB}]}
$$
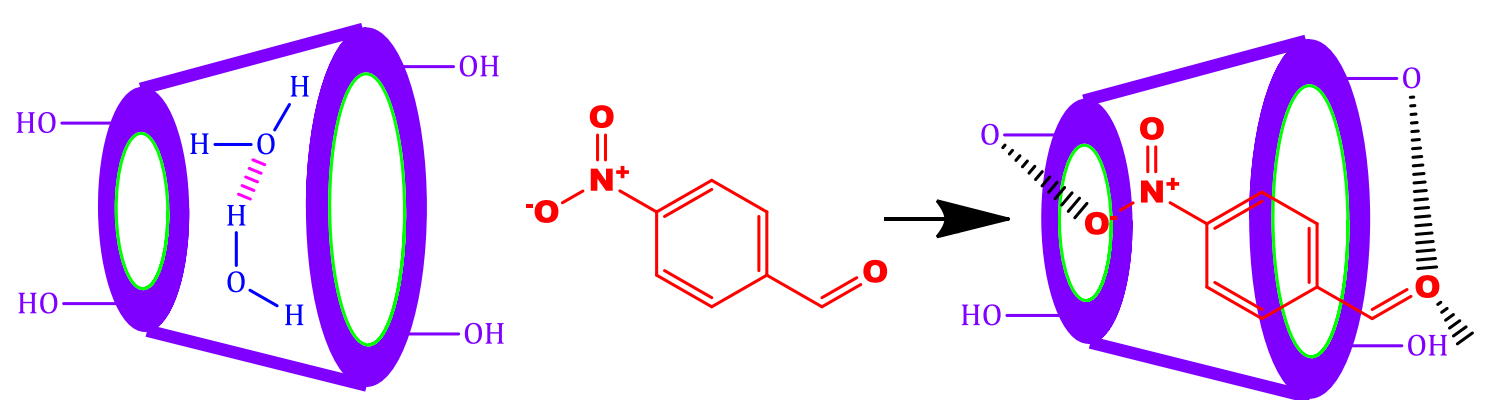

Figure 8. Plausible Schematic representation of mechanism for the formation of 1:1 inclusion complex of PNB with $\beta$ Cyclodextrin.

The equation is valid in case of 1:1 host-guest IC only [21,22]. We get the value of binding constant by dividing the intercept by the slope from double-reciprocal plots. The Ka value is calculated at three different temperatures. The thermodynamic parameters $\Delta \mathrm{G}^{\circ}, \Delta \mathrm{H}^{\circ}$ and $\Delta \mathrm{S}^{\circ}$ for the formation of IC is measured from the famous Van't Hoff equation with the help of association constant $\mathrm{K}_{\mathrm{a}}[23,24]$.

$$
\ln K_{\mathrm{a}}=-\frac{\Delta \mathrm{H}^{\mathrm{o}}}{\mathrm{RT}}+\frac{\Delta \mathrm{S}^{\mathrm{o}}}{\mathrm{R}}
$$

$\ln \mathrm{K}_{\mathrm{a}}$ varies linearly with $1 / \mathrm{T}$. The $\Delta \mathrm{H}^{\circ}$ value depends upon the equilibrium constant at different temperatures. (Table 4) The $\Delta G^{\circ}$ value for the formation of inclusion complex is negative which indicates the process to be thermodynamically favourable. The negative value of $\Delta \mathrm{H}^{\circ}$ shows that the process is exothermic. The entropy value $\Delta \mathrm{S}^{\circ}$ is also negative. The randomness of the molecules decrease due to insertion in the cavity of $\mathrm{CD}$, as a result the $\Delta \mathrm{S}^{\circ}$ value is negative. The higher negative value of $\Delta \mathrm{G}^{\circ}$ overcomes the effect and the whole process is spontaneous. 
Table 4. Association constant (Ka) and thermodynamic parameters $\Delta \mathrm{H} \circ, \Delta \mathrm{S} \circ$ and $\Delta \mathrm{G} \circ$ of different PNB -Cyclodextrin inclusion complexes.

\begin{tabular}{|c|c|c|c|c|c|}
\hline & $\operatorname{Temp}(\mathbf{K})^{\mathbf{a}}$ & $\operatorname{Ka} \times 10^{-3}\left(M^{-1}\right)^{b}$ & $\Delta \mathbf{H}^{\mathbf{o}}\left(\mathbf{k j m o l}^{-1}\right)^{\mathbf{b}}$ & $\Delta \mathbf{S}^{\mathbf{o}}\left(\mathbf{J m o l}^{-1} \mathbf{K}^{-1}\right)^{\mathbf{b}}$ & $\Delta G^{\mathrm{o}}(298.15 \mathrm{~K})\left(\mathrm{kJmol}^{-1}\right)^{\mathrm{b}}$ \\
\hline \multirow{3}{*}{$\mathrm{PNB}+\beta-\mathrm{CD}$} & 298.15 & 1.36 & & & \\
\hline & 303.15 & 1.18 & -20.75 & -9.74 & -17.85 \\
\hline & 308.15 & 1.01 & & & \\
\hline
\end{tabular}

\section{3-6- FT-IR Study}

The encapsulation of PNB by $\beta-C D$ is confirmed by FT-IR study $[25,26]$. There are many changes in the position of peaks in the solid inclusion complexes. The various frequencies of PNB, $\beta-C D$ and PNB $+\beta-C D$ are reported in Table 5. All the spectra are shown in the Figure 9. The spectra of PNB is identified by various characteristic peaks of $-\mathrm{CHO}$, $-\mathrm{NO}_{2}$, aromatic protons at $1707,1535,3424$ etc. Broad characteristic peaks of $-\mathrm{OH}$ at about $3349 \mathrm{~cm}^{-1}$ is present in the spectrum of $\beta-C D$. In the spectra of solid inclusion complexes many peaks of the PNB are either absent or shifted due to change of environment after insertion. The $-\mathrm{O}-\mathrm{H}$ frequency of $\beta-\mathrm{CD}$ are shifted to lower region probably due to involvement of the $-\mathrm{O}-\mathrm{H}$ groups of the host molecules in hydrogen bonding with the PNB molecule. No additional peaks are recognized in the solid inclusion complex which means no chemical reaction occurred between the molecule PNB and CD [27].
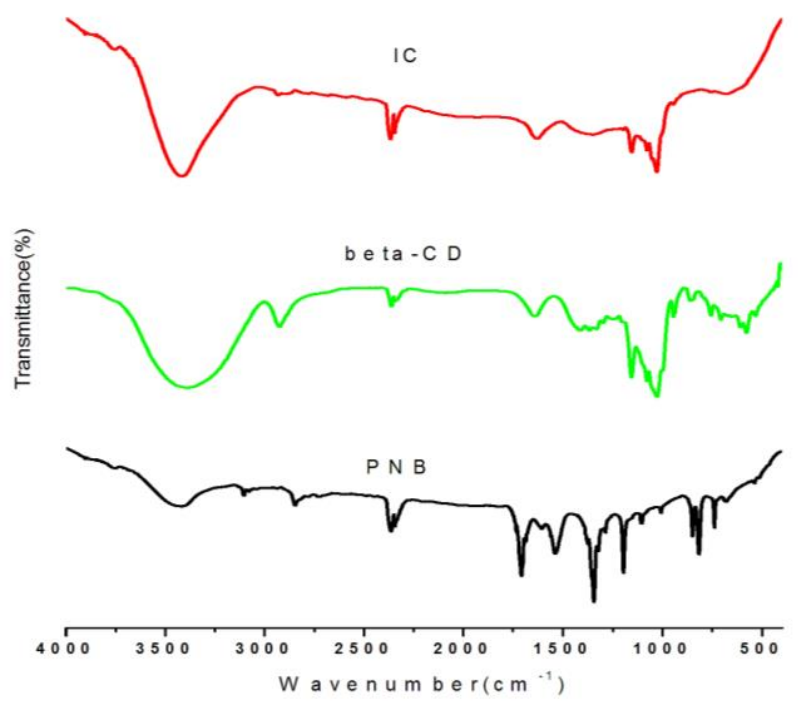

Figure 9. FT-IR spectra of $\beta$-CD, PNB, PNB- $\beta$-CD inclusion complex.

Table 5. Frequencies at FTIR spectra of PNB, $\beta-C D$ and solid inclusion complexes

\begin{tabular}{|c|c|c|}
\hline & Wave Number $/ \mathrm{cm}^{-1}$ & Group \\
\hline \multirow{6}{*}{ PNB } & 816.5 & $-\mathrm{C}-\mathrm{H}$ \\
\hline & 897.3 & $-\mathrm{C}-\mathrm{C}$ \\
\hline & 1346.7 & $-\mathrm{NO}_{2}$ symmetrical stretching \\
\hline & 1535.6 & $-\mathrm{NO}_{2}$ asymmetrical stretching \\
\hline & 1707 & $-\mathrm{CHO}$ \\
\hline & 3424.3 & $=\mathrm{C}-\mathrm{H}$ \\
\hline \multirow{6}{*}{$\beta-\mathrm{CD}$} & 3349.84 & stretching of $\mathrm{O}-\mathrm{H}$ \\
\hline & 2921.52 & stretching of $-\mathrm{C}-\mathrm{H}$ from $-\mathrm{CH}_{2}$ \\
\hline & 1412.36 & bending of $-\mathrm{C}-\mathrm{H}$ from $-\mathrm{CH}_{2}$ and bending of $\mathrm{O}-\mathrm{H}$ \\
\hline & 1157.57 & bending of $\mathrm{C}-\mathrm{O}-\mathrm{C}$ \\
\hline & 1033.51 & stretching of C-C-O \\
\hline & 938.53 & skeletal vibration involving $\alpha$-1,4linkage \\
\hline \multirow{5}{*}{$\mathrm{PNB}+\beta-\mathrm{CD}$} & 2944.6 & stretching of $\mathrm{O}-\mathrm{H}$ of $\beta-\mathrm{CD}$ \\
\hline & 2369.7 & stretching of $-\mathrm{C}-\mathrm{H}$ from $-\mathrm{CH}_{2}$ of $\beta-\mathrm{CD}$ \\
\hline & 1627.8 & $-\mathrm{CHO}$ of PNB \\
\hline & 1354.9 & - $\mathrm{NO}_{2}$ asymmetrical stretching of PNB \\
\hline & 1153.6 & - $\mathrm{NO}_{2}$ symmetrical stretching of PNB \\
\hline
\end{tabular}




\section{3-7- Scanning Electron Study (SEM) Study}

Scanning electron microscopy is a qualitative method used to visualize the surface structure of raw materials or the prepared products [28]. The SEM images of PNB, $\beta$-CD and inclusion complex are shown in Figure 10. As shown in the SEM pictures $\beta$-CD was observed as a plate shaped crystal. PNB appeared also as plate shaped. The inclusion complex was appeared in irregular shapes with variable size, some looks like needle. The size and shape of the new obtained complexes were different from PNB and the host molecule. These changes can be taken as proofs of the formation of new inclusion complexes by molecular encapsulation.

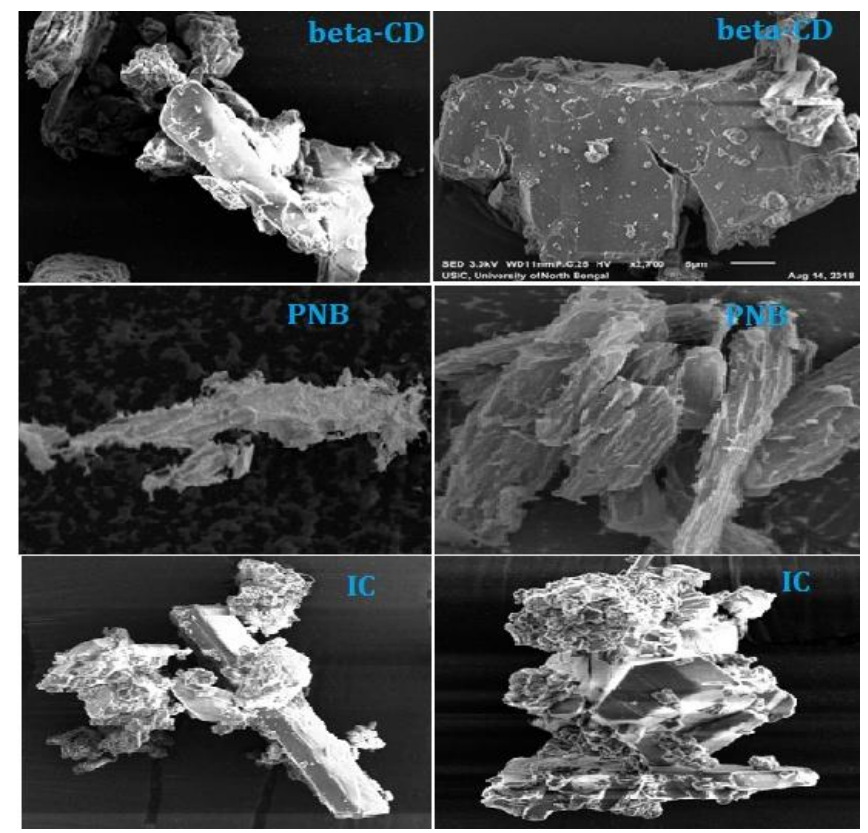

Figure 10. Scanning electron microphotographs (a) $\beta$-CD (b) PNB (c) PNB- $\beta$-CD inclusion complex.

\section{4- Conclusion}

This work confirms that p-nitro benzaldehyde forms inclusion complex with $\beta$-CD in the aqueous medium and in the solid state which can be used as regulatory releaser of this compound. ${ }^{1} \mathrm{H}$ NMR study and SEM study confirms the inclusion phenomenon and its mechanism. Surface tension, conductance and Job plot from UV-visible spectroscopy determines the 1:1 stoichiometric ratio of the IC. FT-IR spectra also supported the formation of IC. The association constants and thermodynamic parameters have been estimated ICs by reliable techniques. There is a drop in $\Delta \mathrm{S}^{0}$, which is overcome by higher negative value of $\Delta \mathrm{H}^{0}$, making the overall inclusion process thermodynamically favourable. This IC has various applications in the field of modern biochemistry and medical science.

\section{5- Acknowledgement}

The authors of this article are grateful to SAP, Department of Chemistry, N.B.U under University Grant Commission (UGC), New Delhi for financial and instrumental assistance to carry out this research work. Dr. Roy is also thankful to UGC, New Delhi for the award of one time grant under BSR for his contribution in the field of modern research work.

\section{6- Conflict of Interest}

The authors declare no conflict of interest.

\section{7- References}

[1] E. Pinho, M. Grootveld, G. Soares, M. Henriques, "Cyclodextrins as encapsulation agents for plant bioactive compounds". Carbohydrate Polymers. 2014, 101, 121-135. doi: 10.1016/j.carbpol.2013.08.078.

[2] K. Dinar, K. Sahra, A. Seridi, M. Kadri, Inclusion complexes of N-sulfamoyloxazolidinones with $\beta$-cyclodextrin: A molecular modeling approach. Chemical Physics Letters, 2014, 595-596, 113-120. doi: 10.1016/j.cplett.2014.02.004.

[3] J. S. Negi, S. Singh, "Spectroscopic investigation on the inclusion complex formation between amisulpride and $\gamma$-cyclodextrin". Carbohydrate Polymers. 2013, 92, 1835-1843. doi: 10.1016/j.carbpol.2012.11.082.

[4] B. Wei, " $\beta$-Cyclodextrin associated polymeric systems: Rheology, flow behavior in porous media and enhanced heavy oil recovery performance”. Carbohydrate Polymers. 2015, 134, 398-405. doi: 10.1016/j.carbpol.2015.08.011. 
[5] A. D. Bani-Yaseen, A. Mo'ala, "Self assembled materials: design strategies and drug delivery perspectives." Spectrochimica Acta Part A: Molecular and Biomolecular Spectroscopy. 2014, 131, 424-431.

[6] P. Job, "Formation and Stability of Inorganic Complexes in Solution”. Ann. Chim. 1928, 9, 113-203.

[7] J. S. Renny, L. L. Tomasevich, E. H. Tallmadge, D. B. Collum, "Method of Continuous Variations: Applications of Job Plots to the Study of Molecular Associations in Organometallic Chemistry'. Angew. Chem. Int. Ed. 2013, 52, 11998 - 12013. doi: 10.1002/anie.201304157.

[8] J. V. Caso, L. Russo, M. Palmieri, G. Malgieri, S. Galdiero, A. Falanga, C. Isernia, R. Iacovino, "Investigating the inclusion properties of aromatic amino acids complexing beta-cyclodextrins in model peptides." Amino Acids. 2015, 47, $2215-2227$. doi: 10.1007/s00726-015-2003-4.

[9] M. N. Roy, S. Saha, S. Barman, D. Ekka, "Host-Guest Inclusion Complexes of RNA Nucleosides inside Aqueous Cyclodextrins Explored by Physicochemical and Spectroscopic Methods.” RSC Adv. 2016, 6, 8881-8891. doi: 10.1039/C5RA24102B.

[10] M. N. Roy, S. Saha, M. Kundu, B. C. Saha, S. Barman, "Exploration of inclusion complexes of neurotransmitters with $\beta$ cyclodextrin by physicochemical techniques." Chemical Physics Letters. 2016, 655-656, 43-50. doi: 10.1016/j.cplett.2016.05.031.

[11] L. Wang, S. Li, P. Tang, J. Yan, K. Xu, H. Li, "Characterization and evaluation of synthetic riluzole with $\beta$-cyclodextrin and 2,6-di-O-methyl- $\beta$-cyclodextrin inclusion complexes”. Carbohydrate Polymers. 2015, 129, 9-16. doi: 10.1016/j.carbpol.2015.04.046.

[12] S. Saha, T. Ray, S. Basak, M. N. Roy, "NMR, surface tension and conductivity studies to determine the inclusion mechanism: thermodynamics of host-guest inclusion complexes of natural amino acids in aqueous Cyclodextrins." New J. Chem. 2016, 40, 651-661. doi: 10.1039/C5NJ02179K.

[13] T. Wang, M.D. Wang, C. Ding, J. Fu, "Mono-benzimidazole functionalized $\beta$-cyclodextrins as supramolecular nanovalves for pH-triggered release of p-coumaric acid". Chem. Commun. 2014, 50, 12469-12472. doi: 10.1039/C4CC05677A.

[14] Y. Gao, X. Zhao, B. Dong, L. Zheng, N. Li and S. Zhang, "Inclusion complexes of $\alpha$-cyclodextrin with ionic liquid surfactants". J. Phys. Chem. B. 2006, 110, 8576-8581. doi: 10.1021/jp057478f.

[15] M. N. Roy, D. Ekka, S. Saha, M. C. Roy, "Host-guest inclusion complexes of $\alpha$ and $\beta$-cyclodextrins with $\alpha$-amino acids". RSC Adv. 2014, 4, 42383-42390. doi: 10.1039/C4RA07877B.

[16] A. Pineiro, X. Banquy, S.P. Casas, E. Tovar, A. Garcia, A. Villa, A. Amigo, A.E. Mark, M. Costas, "On the characterization of host-guest complexes: surface tension, calorimetry, and molecular dynamics of cyclodextrins with a non-ionic surfactant". J. Phys. Chem. B. 2007, 111, 4383-4392. doi: 10.1021/jp0688815.

A. Apelblat, E. Manzurola, Z. Orekhova, "Electrical conductance studies in aqueous solutions with glutamic ions". J. Solut. Chem. 2007, 36, 891-900. doi: 10.1007/s10953-007-9156-z.

[17] T. Qian, C. Yu, S. Wu, J. Shen, "Nanoparticles coated polystyrene/reduced graphite oxide microspheres with improved dispersibility and electrical conductivity for dopamine detection". Colloids Surf. B. 2013, 112, 310-314. doi: 10.1016/j.colsurfb.2013.08.005.

[18] A. Roy, S. Saha, M. N. Roy, "Study to explore host-guest inclusion complexes of Cyclodextrins with biologically active molecules in aqueous environment". Fluid Phase Equilibria. 2016, 425, 252-258. doi: 10.1016/j.fluid.2016.06.013.

[19] F. Cramer, W. Saenger, H. Spatz, "Inclusion compounds. The formation of inclusion compounds of $\alpha$-cyclodextrin in aqueous solutions. Thermodynamics and kinetics”. J. Am. Chem. Soc. 1967, 89, 14-20. doi: 10.1021/ja00977a003.

[20] J. V. Caso, L. Russo, M. Palmieri, G. Malgieri, S. Galdiero, A. Falanga, C. Isernia, R. Iacovino, "Investigating the inclusion properties of aromatic amino acids complexing beta-cyclodextrins in model peptides". Amino Acids. 2015, 47, $2215-2227$. doi: 10.1007/s00726-015-2003-4.

[21] H. A. Benesi, J. H. Hildebrand, "A Spectrophotometric investigation of the interaction of iodine with aromatic hydrocarbons". J. Chem. Soc. 1949, 71, 2703-2707. doi: 10.1021/ja01176a030.

[22] Y. Dotsikas, E. Kontopanou, C. Allagiannis, Y. L. Loukas, "Interaction of 6-p-toluidineylnaphthalene-2-sulphonate with $\beta$ cyclodextrin”. J. Pharm. Biomed. Anal. 2000, 23, 997-1003. doi: 10.1016/S0731-7085(00)00392-7.

[23] Y. He, X. Shen, "Interaction between $\beta$-cyclodextrin and ionic liquids in aqueous solutions investigated by a competitive method using a substituted 3H-indole probe". Journal of Photochemistry and Photobiology, A: Chemistry. 2008, 197, $253-259$. doi: 10.1016/j.jphotochem.2008.01.001.

[24] C. Xiao, K. Li, R. Huanga, G. Hea, J. Zhang, L. Zhu, Q. Yang, K. Jiang, Y. Jin, J. Lin, "Investigation of inclusion complex of Epothilone A with Cyclodextrins”. Carbohydrate Polymers. 2014, 102, 297-305. doi: 10.1016/j.carbpol.2013.11.049. 
[25] T. Stalin, K. Srinivasan, K. Sivakumar, S. Radhakrishnan, “2,6-Dinitroaniline and $\beta$-cyclodextrin inclusion complex properties studied by different analytical methods" Carbohydrate Polymers. 2014, 107, 72-84. doi: 10.1016/j.carbpol.2014.07.062.

[26] K. P. Sambasevam, S. Mohamad, N. M. Sarih, N. A. Ismail "Synthesis and characterization of the inclusion complex of $\beta$ cyclodextrin and azomethine”. Int. J. Mol. Sci. 2013, 14, 3671-3682. doi: 10.3390/ijms14023671.

[27] R. Periasam, S. Kothainayaki, R. Rajamohan, K. Sivakumar, "Spectral investigation and characterization of host - guest inclusion complex of 4,4' -methylene-bis(2-chloroaniline) with beta-cyclodextrin” . Carbohydrate Polymers. 2014, 114, 558566. doi: 10.1016/j.carbpol.2014.08.006.

[28] Jian-qiang Zhang, Kun-ming Jiang, Kun An, Si-Hao Ren, Xiao-guang Xie, Yi Jin, Jun Lin, "Novel water-soluble fisetin/Cyclodextrins inclusion complexes: Preparation, characterization, molecular docking and bioavailability Carbohydrate Research. 2015, 418, 20-28. doi: 10.1016/j.carres.2015.09.013. 